\title{
A não resposta no Atlas Linguístico do Português em Áreas Indígenas (ALiPAI): um olhar sobre o campo semântico corpo humano
}

\author{
The non response in the Atlas Linguístico do Português em Áreas \\ indígenas (ALiPAI): a look at the semantic field human Body
}

\author{
Eliane Oliveira da Costa ${ }^{1}$ \\ https://orcid.org/0000-0003-2933-5341
}

Abdelhak Razky²

https://orcid.org/0000-0001-9250-8917

\section{DOI: 10.26512/rbla.v12i1.29751}

Recebido em abril/2020 e aceito em maio/2020

\section{Resumo}

Este artigo consiste em um estudo sobre a não resposta no corpus do projeto Atlas Linguístico do Português em Áreas Indígenas (ALiPAI), a partir das questões 89 (pálpebras) e 117 (rótula) do campo semântico Corpo humano do Questionário Semântico-Lexical (QSL) aplicado pelos pesquisadores do projeto. Os dados foram coletados in loco nas Terras Indígenas Trocará, Nova Jacundá e Sororó, no estado do Pará, e Cana Brava, no estado do Maranhão. Os resultados apresentam alto índice de não resposta para ambas as questões consideradas; mostram que os dados analisados são tímidos para explicar a não resposta, mas podem indicar o perfil do colaborador (no que tange a fatores sociais como idade e escolaridade) como ponto importante quando do seu entendimento e refletem a ocorrência da não resposta relacionando-a à aspectos referentes à extensão do QSL e à ordem de aplicação dos questionários, à história e à cultura dos povos indígenas participantes desta pesquisa e ao conhecimento de mundo que possuem. Além disso, a não resposta estabelece-se como um tópico de reflexão metodológica no que tange a instrumentos de coleta de dados, à ampliação de variáveis e de colaboradores na sua compreensão no âmbito da pesquisa geossociolinguística.

Palavras-chave: ALiPAI. Não resposta. Pálpebras. Rótula. Geossociolinguística.

1 Linguista, pesquisadora no Projeto "Geossociolinguística e Socioterminologia (GeoLinTerm)". E-mail: elianecosta21@yahoo.com.br.

2 Linguista, professor na Universidade de Brasília, Universidade Federal do Pará. Conselho Nacional de Desenvolvimento Científico e Tecnológico (CNPq). E-mail: arazky@gmail. com. 


\begin{abstract}
This article focuses on the non response to two questions form the corpus of Atlas Linguístico do Português em Áreas Indígenas (ALiPAI) based on the Semantic-Lexical Questionnaire (QSL) applied by the researchers of the project. The analysis of the nonresponse refers to questions 89 (eyelids) and 117 (kneecap) of the semantic field 'Human Body'. The data were collected in loco in the indigenous lands Trocará, Nova Jacundá and Sororó in the state of Pará, and Cana Brava in the state of Maranhão. The results show a high rate of non-response for both questions considered and a low amount of analyzed data to explain the non-response. Still, they indicate that participants' profiles, regarding social factors such as age and education, are important factors to understand the nonresponse. This can be explained by aspects related to the extension of the QSL, the order of application of the questionnaires, the history and culture of the indigenous peoples participating in this research and the knowledge of the world they have. In addition, the non response is put forward as a point of methodological reflection with regard to data collection instruments, the expansion of variables and collaborators to understand it within the context of geosociolinguistic research.
\end{abstract}

Keywords: ALiPAI. Non response. Eyelids. Patella. Geosociolinguistics.

\title{
1. Introdução
}

Este artigo propõe uma reflexão sobre a não resposta no campo semântico Corpo humano do Questionário Semântico-Lexical (QSL) aplicado pelos pesquisadores do Atlas Linguístico do Português em Áreas Indígenas (ALiPAI), no que concerne a duas questões que o integram: a de número 89 (... esta parte aqui que cobre o olho? Apontar) e a de número 117 (... o osso redondo que fica na frente do joelho?).

O tema não resposta, no âmbito das pesquisas desenvolvidas por pesquisadores do Atlas Linguístico do Brasil (ALiB), já foi desenvolvido por Aguilera \& Yida (2008), em um trabalho intitulado Projeto ALiB: uma análise das respostas e das não-respostas de informantes das capitais, e por Oliveira, Costa \& Paz (2018), em um estudo intitulado Reinterpretando Vazios Dialetológicos no Norte do Brasil.

A discussão que se busca neste estudo insere-se na mesma perspectiva das pesquisas realizadas pelas autoras supracitadas, procurando refletir sobre as causas do alto índice de não resposta entre os indígenas das etnias Asuriní do Tocantins, Guaraní Mbyá, Suruí Aikewára e Guajajára, quando da emissão de uma resposta às questões relativas aos conceitos de pálpebras e rótula. Nesse sentido, Cardoso (2016) explica que tanto a atestação de denominações quanto a ausência de registros na área investigada são importantes para a Dialetologia, haja vista que os espaços vazios também informam sobre a língua pesquisada. Dessa forma, este trabalho pode contribuir para melhor conhecimento da variedade étnica da língua portuguesa falada por esses povos, bem como da situação das próprias línguas indígenas. 
Os dados deste estudo foram coletados in loco nas Terras Indígenas Trocará/ PA, Nova Jacundá/PA, Sororó/PA e Cana Brava/MA com a aplicação do QSL à colaboradores estratificados segundo sexo, idade e escolaridade. Os dados analisados pertencem ao projeto ALiPAI, que se estabelece como um corpus significativo do português falado nessas comunidades indígenas.

$\mathrm{O}$ artigo estrutura-se da seguinte maneira: na primeira seção, apresentam-se algumas reflexões sobre a não resposta em estudos geolinguísticos. Na segunda seção, descrevem-se aspectos metodológicos deste estudo e, por fim, na terceira seção, apresenta-se a análise dos dados considerados, seguida das considerações finais dos autores.

\section{A não resposta nos inquéritos de estudos geolinguísticos}

Voltar a atenção para o fato da não resposta na pesquisa geolinguísta significa desviar-se dos pontos que têm sido debatidos pelos pesquisadores da área até o presente momento, haja vista que resultam deles estudos em que são feitas análises de dados linguísticos (fonético-fonológicos, lexicais etc.). Tomando um caminho de reflexão distinto, os trabalhos de Aguilera \& Yida (2008) e o de Oliveira, Costa \& Paz (2018), que serão apresentados a seguir, em conjunto, mostram a importância de se refletir sobre a não resposta, observando-a no percurso histórico e abordando-a numa perspectiva metodológica.

O trabalho de Aguilera \& Yida (2008), constitui uma pesquisa sobre o conjunto de respostas dadas pelos informantes das vinte e cinco capitais brasileiras, corpus do ALiB, a partir do Questionário Fonético-Fonológico (QFF), dando ênfase à análise da ausência de resposta, sob as dimensões diatópica, diagenérica, diageracional e diastrática. As autoras nesse sentido, afirmam o seguinte:

Dentre as dezenas de trabalhos que já foram desenvolvidos a partir dos dados coletados pelo ALiB, nenhum ainda se voltou para o problema da ausência de resposta ocorrida durante a recolha. Esta questão, no entanto, é crucial no momento da cartografação dos dados pelas lacunas que deixa nos espaços destinados ao preenchimento com as variantes buscadas (Aguilera \& Yida 2008, 17).

A ausência de resposta é entendida pelas pesquisadoras como não resposta ou resposta inadequada, e as hipóteses que consideram para sua ocorrência são as seguintes: a) instrumentos de coleta de dados e formulação das questões, b) habilidade e preparação do pesquisador e c) perfil do informante. As estudiosas descartaram o fator cansaço do informante pelo fato de o QFF ser o primeiro questionário a ser aplicado e comportar apenas 159 questões. Independentemente das hipóteses, as autoras chamam a atenção para mais um fato: 
O que não se discutiu até hoje, porém, é o limite aceitável de abstenções. Não se sabe, igualmente, como os geolinguístas do século passado reagiam diante das não-respostas, que deveriam ser comuns, principalmente porque os questionários eram muito extensos, chegando alguns a 5000 questões. Quanto aos atlas estaduais brasileiros, publicados ou concluídos, diante das reiteradas não-respostas, os autores explicam em notas os motivos das abstenções: problemas técnicos com o gravador, descuido do entrevistador, cansaço, timidez, esquecimento e desconhecimento do referente por parte do informante (Aguilera \& Yida 2008, 28).

As estudiosas apresentam cada uma das hipóteses que definiram para discussão e, quanto ao instrumento de coleta de dados e formulação das questões (a), entendem que "o problema não parece, pois, estar no número de questões (435 ao todo) nem na formulação das perguntas, uma vez que as mais complicadas contêm mais de uma sugestão" (Aguilera \& Yida 2008, 27-28). No que se refere à habilidade e preparação do entrevistador (b), explicam que além de apresentar naturalmente habilidade, deve ser preparado com rigor, o que demandou tomada de medidas pelo Comitê Nacional do ALiB, tais como solicitar aos diretores das equipes regionais que preparassem sua equipe e limitar o número de pessoas destinadas à realização de entrevista. No que diz respeito ao perfil do informante (c), apontam fatores de natureza social, como baixa escolaridade e conhecimento de mundo reduzido; psicológica, como timidez, cansaço, doença e falta de interesse; e pessoal, como falta de tempo e compromissos concomitantes ao horário da entrevista.

Nesse mesmo viés temático, Oliveira, Costa \& Paz (2018), por sua vez, desenvolveram um trabalho em que estudaram os vazios dialetológicos no Norte do Brasil a partir de duas questões, sendo uma do QFF (32/Abóbora) ${ }^{3}$ e a outra do QSL (41/Camomila) ${ }^{4}$. Do mesmo modo que Aguilera \& Yida (2008), utilizaram o corpus do $\mathrm{ALiB}$, mas apenas os dados relativos às capitais nortistas. Os questionários do ALiB são postos no centro da discussão e sobre eles as autoras entendem que "têm a árdua tarefa de dar conta da diversidade linguística e cultural do país" (Oliveira, Costa \& Paz 2018, 13) e, nesse sentido, compartilham a seguinte experiência:

3 ... aquilo que dá no chão, grande (mímica), com uma casca grossa vermelho-amarelada por dentro e que se cozinha para comer, fazer doce? (Comitê Nacional do Projeto ALiB 2001: 9)

4 ... umas florezinhas brancas com miolo amarelinho, ou florezinhas secas que se compram na farmácia ou no supermercado e servem para fazer um chá amarelinho, cheiroso, bom para dor de barriga de nenê/bebê e até de adulto e também para acalmar? Mostrar" (Comitê Nacional do Projeto ALiB 2001, 24) 
Voltando à experiência vivenciada, lembramos que a situação referiase à questão 32 do QFF: ... aquilo que dá no chão, grande (mímica), com uma casca grossa vermelho-amarelada por dentro e que se cozinha para comer, fazer doce? (Comitê Nacional do Projeto ALiB 2001, p: 9). A resposta esperada, 'abóbora', não era respondida pelo entrevistado. Assistíamos e víamos que não seria facilmente respondida, pois havia informações na pergunta que não faziam parte da cultura local ou faltava alguma informação na questão que pudesse ativar na memória aquilo que estava sendo descrito, algo mais específico da cultura alimentar do Norte do país. Mesmo já tendo usado o referido questionário, ainda não tínhamos nos dado conta disso. Pedimos que a entrevistadora fizesse uma pausa e incluísse na pergunta a seguinte informação: ... vocês costumam colocar aqui no cozidão. A resposta foi imediata (Oliveira, Costa \& Paz 2018, 14).

As estudiosas caracterizaram as perguntas e as respostas feitas/dadas pelos inquiridores/informantes e, no âmbito das respostas ${ }^{5}$, definiram dois tipos: sem resposta, quando o informante não responde ou diz que não sabe, e não resposta, quando a resposta dada pelo informante não condiz com o conceito veiculado pela questão. Ao nível de hipóteses, afirmam que a principal explicação dos fatos "é de que há pressão dos fatores sociais, não apenas dos fatores clássicos, mas também da avaliação social das formas linguísticas, bem como do fator histórico-cultural, parte integrante da realidade linguístico-cultural" (Oliveira, Costa e Paz 2018, 12).

As pesquisadoras discutem cada uma das questões que selecionaram para análise, à luz da hipótese pensada e do modo como caracterizaram perguntas e respostas, sob as perspectivas social, histórica e cultural e, em conclusão, afirmam que o resultado da pesquisa que desenvolveram apontam a necessidade de se ter uma equipe que se caracterize pela multidisciplinariedade e representatividade regional (quando da elaboração de questionários), para a positividade da reformulação das questões (na hora do inquérito), para a consideração dos fatores pragmático e cultural e para a relevância do que se aprende em campo (que também deve ser levado em consideração no momento de reflexão sobre questões e questionários).

Conforme podemos observar, por meio da exposição do trabalho de Aguilera \& Yida (2008) e de Oliveira, Costa \& Paz (2018), as discussões sobre a não reposta é bastante produtiva e pertinente, à medida que ajudam na reflexão do fazer geolinguístico, e o dado relativo à não resposta é real e implica nos resultados pretendidos com as pesquisas geolinguísticas e, consequentemente, na imagem cartográfica elaborada, sendo muito oportuno o fragmento a seguir:

5 No âmbito das perguntas, foram caracterizadas: pergunta sem reformulação, pergunta com reformulação e natureza da reformulação. 
Necessário destacar que dois aspectos fundamentais estão na base dos estudos dialetais. De um lado, o reconhecimento das diferenças e das igualdades que a língua reflete e o estabelecimento das relações entre as diversas manifestações linguísticas documentadas. De outro, o confronto entre a presença e a ausência de dados registrados, circunscritos a espaços fixados, importando, para o seu objetivo precípuo, tanto a atestação de denominações identificadas na área como a ausência de registros, porque os espaços vazios também informam sobre a língua pesquisada (Cardoso 2016, 15).

Trazer essa reflexão sobre a não resposta para o contexto do ALiPAI é justificável pelo fato de esse projeto de atlas envolver espaços geográficos, indivíduos, organizações sociais e culturais que por muito tempo estiveram fora do escopo metodológico dos estudos geolinguístico. Desse modo, neste trabalho, adotam-se as hipóteses constantes dos estudos apresentados nesta seção para se desenvolver tal reflexão.

\section{Metodologia}

A rede de pontos deste estudo abrange quatro Terras Indígenas, sendo três localizadas no Pará, Trocará/Tucuruí, Nova Jacundá/Rondon do Pará e Sororó/ São Geraldo do Araguaia, e uma no Maranhão, Cana Brava/Barra do Corda ${ }^{6}$. Os dados apresentados e analisados neste artigo integram o banco de dados do projeto ALiPAI e foram coletados nas referidas localidades por meio da aplicação do QSL a colaboradores das etnias Asuriní do Tocantins, Guaraní Mbyá, Suruí Aikewára e Guajajára, considerando as dimensões diatópica (Terras Indígenas), diageracional ( 5 a 10 anos - Faixa etária $\mathrm{C}, 18$ a 37 anos - Faixa etária A, 47 a 75 anos - Faixa etária B), diagenérica (masculino e feminino) e diastrática (não escolarizados ou escolarizados até a $8^{\mathrm{a}}$ série $\left(9^{\circ}\right.$ ano) e escolarizados a partir do $1^{\circ}$ ano do ensino médio), além da dialingual. No total, responderam ao QSL 33 indivíduos, sendo oito Asuriní, nove Suruí, oito Guaraní e oito Guajajára ${ }^{7}$, sendo que o ALiPAI previa dez colaboradores por localidade.

O QSL utilizado no ALiPAI foi o mesmo do projeto ALiB, sem nenhuma alteração estrutural. No entanto, com o objetivo de se obter o item lexical esperado em língua portuguesa e em língua indígena, faziam-se duas perguntas, desta forma: "...aquele inseto pequeno, de perninhas compridas, que canta no ouvido das pessoas, de noite? E na sua língua?" Além do mais, adotou-se o método da "pesquisa em três tempos" (Radtke \& Thun 1996). Com essas

6 Na TI Trocará, estão os Asuriní do Tocantins; na Nova Jacundá, os Guaraní Mbyá; na Sororó, os Suruí Aikewára e, na Cana Brava, os Guajajára.

7 Essa configuração numérica deu-se pelo fato de não ter sido possível, à época da pesquisa, encontrar indivíduos que se enquadrassem em alguns dos perfis sociolinguísticos definidos. 
mesmas técnicas aplicou-se o Questionário fonético-fonológico (QFF), também do ALiB, com complementações, conforme Razky, Guedes \& Costa (2018).

Além do QFF e do QSL, aplicou-se o Questionário Sociolinguístico (QS), que possibilitou a coleta de dados sobre o uso das línguas consideradas por meio de perguntas tais como: "Em que locais e situações você fala português?", "Em que locais e situações você fala (LI)?", "Todas as pessoas daqui falam (LI)?" e "Quando vem uma visita, que língua(s) você(s) usa(m)? E se a visita fala só o português ou só o (LI)?", contando as três primeiras com sugestões de resposta. Ademais coletaram-se relatos de experiência pessoal em língua portuguesa e indígena, solicitados aos colaboradores adultos.

Em relação a dupla aplicação do QSL, tendo em vista que o interesse do ALiPAI é o português falado por indígenas, consideraram-se neste trabalho apenas os dados de língua portuguesa, embora em alguns momentos a menção à língua indígena seja oportuna. Em relação aos dados coletados com o QS, foram analisados no trabalho de Costa (2018), cujos resultados serão referidos na seção da análise.

Neste estudo, enquadram-se como não resposta os seguintes casos: a) quando o colaborador diz que não sabe ou não lembra, b) quando simplesmente não responde e c) quando ele dá uma resposta que não corresponde ao conceito da questão.

Devido às configurações de extensão do artigo, analisam-se na próxima seção somente as cartas diatópicas referentes aos itens lexicais selecionados para este estudo, pálpebras e rótula. Os resultados documentados nas cartas estratificadas (dimensões diageracional, diagenérica e diastrática) serão apresentados em conjunto por meio de tabela.

\section{Análise dos dados}

Ao estudar a variação lexical do português falado por indígenas nos estados do Pará e Maranhão, dados do ALiPAI, Costa (2018) observou quatro tendências lexicais, a saber: i) a das variantes menos frequentes, ii) a das variantes locais, iii) a das variantes que tendem a não ter expressividade dialetal e iv) a do contínuo dialetal. Este estudo dedica-se às variantes menos frequentes, ou seja, aquelas que ocorrem sem expressividade quantitativa, gerando uma imagem cartográfica em que se destaca a não resposta, como é o caso das variantes documentadas nas cartas 001 (Figura 1) e 002 (Figura 2), referentes, respectivamente, aos itens lexicais pálpebras e rótula . 


\section{- PÁLPEBRAS}

Imagem 1. Carta 001/Denominações para pálpebras
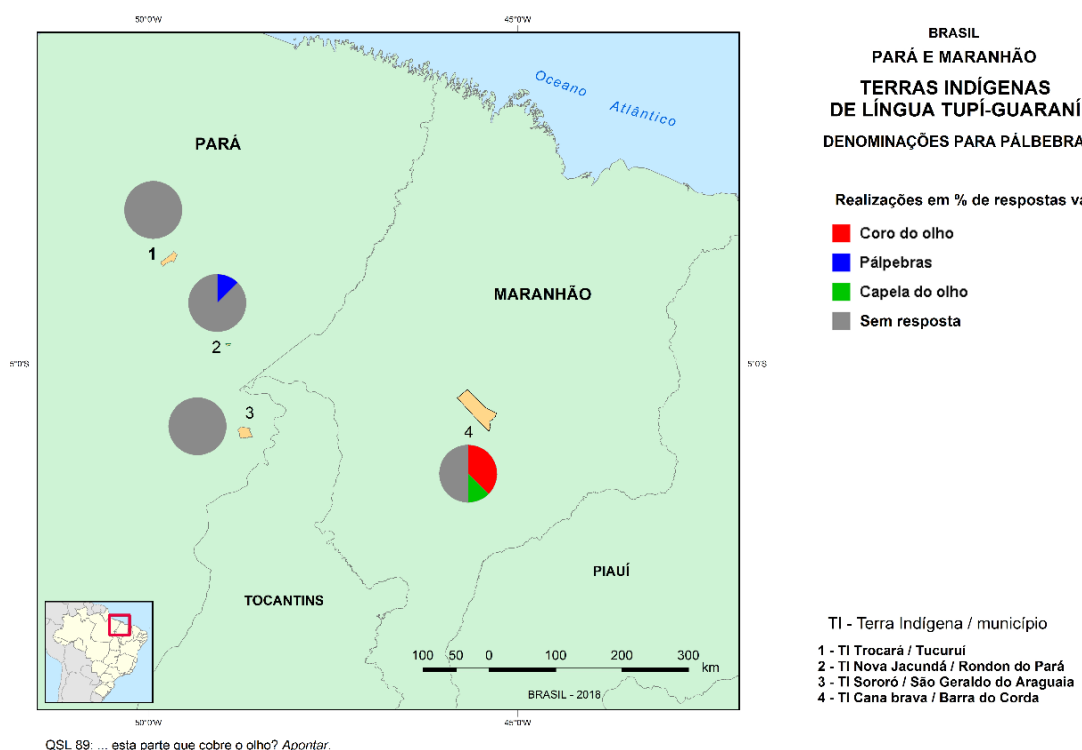

Realizações em \% de respostas válidas

Coro do olho

Pálpebras

Capela do olho

Sem resposta

TI - Terra Indigena/município

1. T/ Trocará/ Tucurui

- Tl Nova Jacundá / Rondon do Pará

2. TI Nova Jacundá/ Rondon do Pará
3. TI Sororó / São Geraldo do Araguaia
4. TI Cana brava / Barra do Corda

QSL 89 ... esta oarte que cobre o olho? Apontar.

\section{Gráfico 1. Pálpebras/não resposta por Terra Indígena}

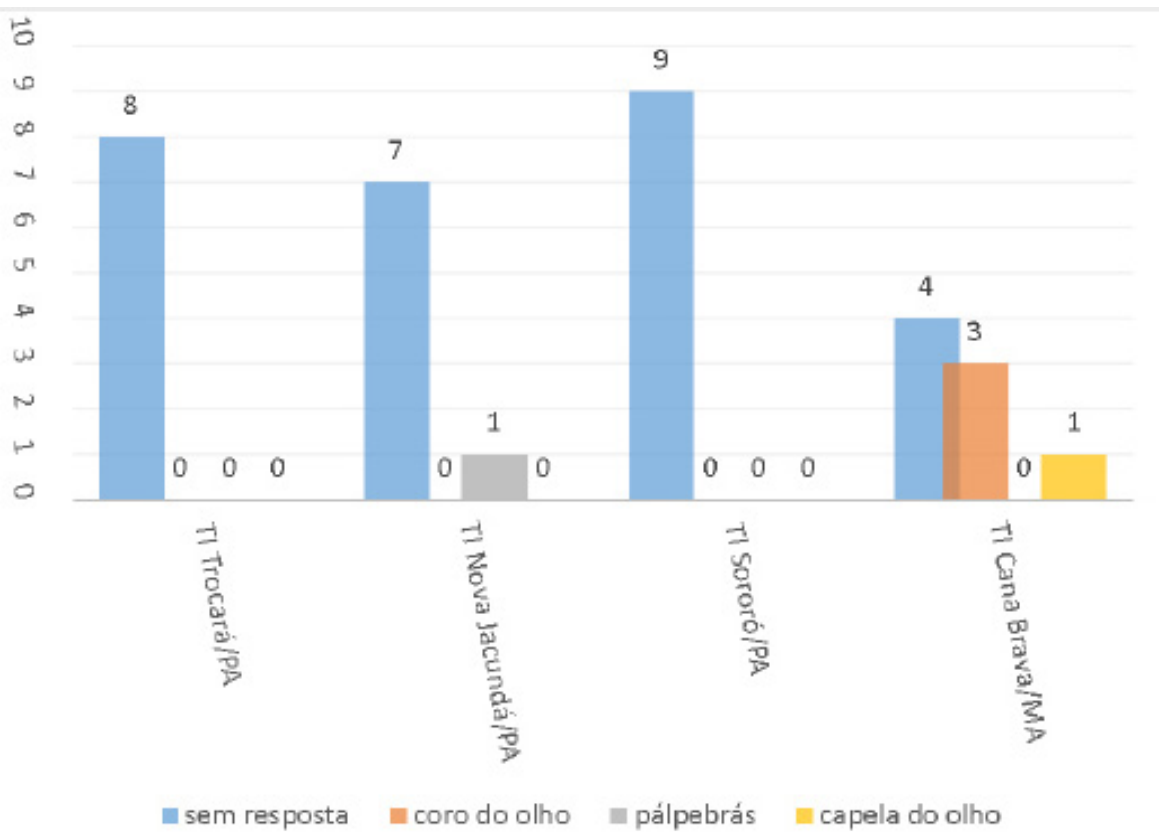


A figura e o gráfico 1 registram um total de três variantes lexicais para denominar a parte do corpo humano que cobre o olho, sendo coro do olho, com três ocorrências, todas na Terra Indígena (doravante TI) Cana Brava, a mais frequente. Além dessa variante, registram-se, ainda, pálpebras (ponto 2/ TI Nova Jacundá) e capela do olho (ponto 4/TI Cana Brava), ambas com uma ocorrência. A não resposta destaca-se como o fato mais recorrente, embora no ponto 4, onde moram os Guajajára, no Maranhão, coro do olho apresente quase o mesmo número de ocorrências de não respostas.

- RÓTULA

Imagem 2. Carta 002/Denominações para rótula
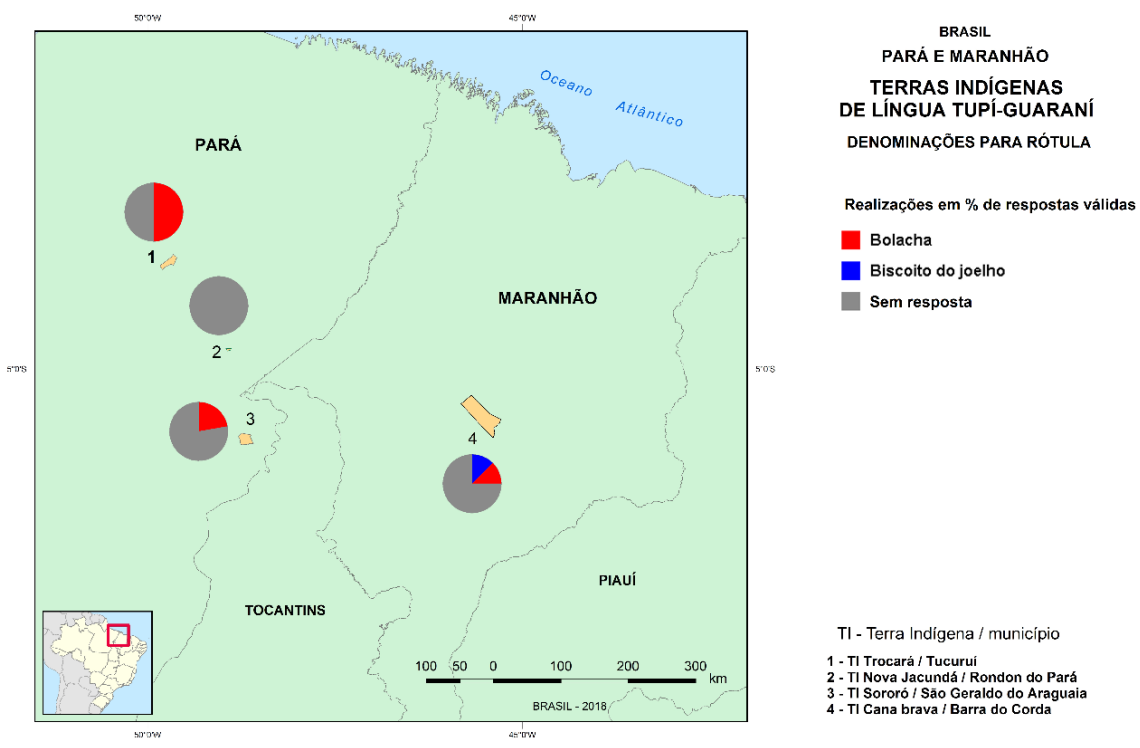

QSL 117: $\ldots . .0$ osso redondo que fica na frente do joelho?

Gráfico 2. Rótula//não resposta por Terra Indígena

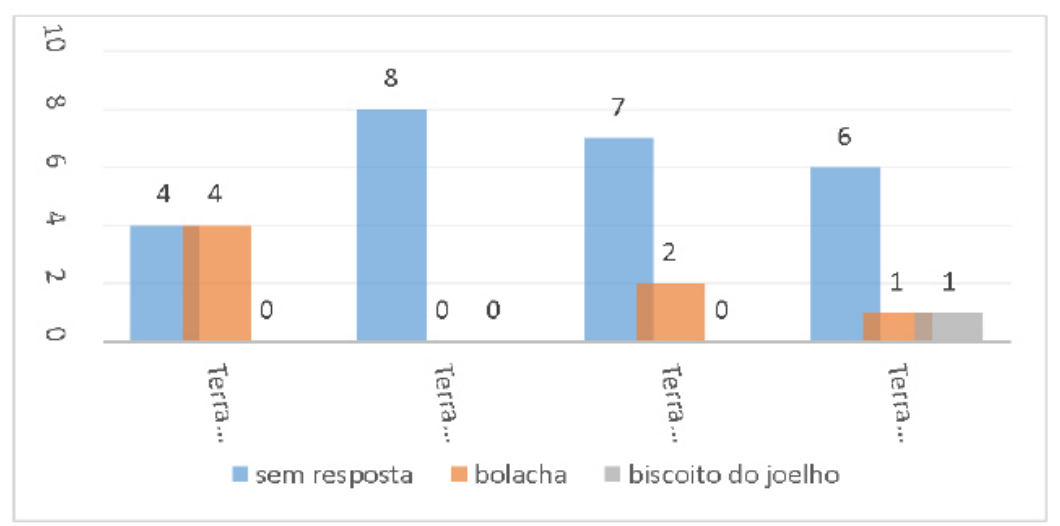


A figura e o gráfico 2 registram um total de duas variantes lexicais para denominar o osso redondo que fica na frente do joelho, sendo bolacha, com sete ocorrências, quatro em Trocará, duas em Sororó e uma em Cana Brava, a mais frequente, seguida de biscoito do joelho, com uma ocorrência, em Cana Brava. O número de não resposta destaca-se em todos os pontos desta pesquisa, com exceção da TI Trocará (dos indígenas Asuriní do Tocantins), onde o número de registro de não resposta e da variante lexical bolacha equivalem-se.

O número total de resposta e de não resposta (Gráfico 3), considerando os trinta e três indígenas entrevistados e ambos os itens lexicais estudados, mostra, com mais clareza, a expressividade da não resposta nos dados analisados.

\section{Gráfico 3. Número de resposta e de não resposta por item lexical}

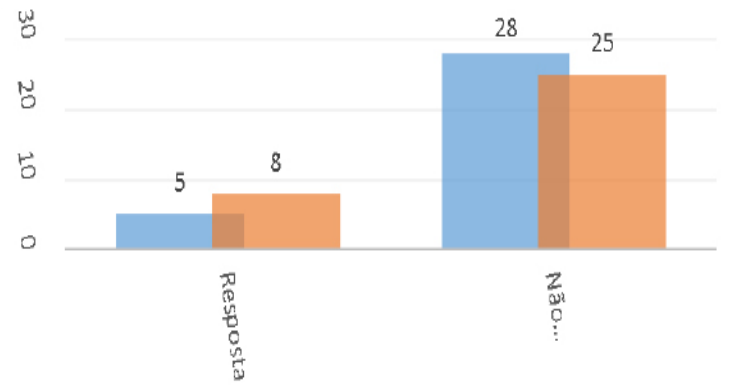

- Pálbebras nótula

Em ambos os casos (pálpebras e rótula), a não resposta é uma realidade que chama a atenção. Nesse sentido, refletindo-se as hipóteses que Aguilera \& Yida (2008) levantaram ao estudarem a não resposta no corpus do ALiB no contexto da pesquisa geolinguística em áreas indígenas, ressalta-se, quanto aos instrumentos de coleta de dados e à formulação das questões (hipótese a), a colocação segundo a qual "os questionários [do ALiB] estruturados, ou mesmo os roteiros de entrevista, são elaborados criteriosamente visando à obtenção do maior número de respostas, com a expectativa até de que todas elas sejam preenchidas" (Aguilera \& Yida 2008: 27). De fato, as duas questões consideradas neste estudo, a 89 (... esta parte aqui que cobre o olho? Apontar) e a 117 (... o osso redondo que fica na frente do joelho?), são bem simples, além de se beneficiarem do fator palpável, ou seja, o inquiridor pode apontar/tocar no referente cujo nome está sendo solicitado, visto que são partes do corpo humano.

Em relação à habilidade natural do pesquisador e sua preparação (hipótese b), destaca-se, em primeiro lugar, a experiência de escuta e de transcrição de dados dos primeiros pesquisadores do ALiPAI, não só no que se refere aos dados do ALiB, mas também aos do Atlas Léxico Sonoro do Pará (ALeSPA), o que os possibilitou conhecer os questionários utilizados nesses projetos, observar 
como se dá a sua aplicação e refletir sobre ela ${ }^{8}$. Em segundo lugar, o cuidado dos mesmos com o funcionamento dos equipamentos utilizados para gravar as entrevistas e com o campo de pesquisa.

No que tange ao perfil do informante (hipótese c), incluem-se fatores de natureza social, psicológica e pessoal.

Quanto aos fatores de natureza social, os dados registrados nas cartas estratificadas referentes aos itens lexicais pálpebras e rótula, expostos a seguir (Tabelas 1 e 2), mostram a não resposta nas dimensões diastrática, diagenérica e diageracional.

Tabela 1. Não resposta por dimensão social/pálpebras

\begin{tabular}{|l|c|c|c|c|c|c|c|}
\hline \multicolumn{10}{|c|}{ PÁLPEBRAS } \\
\hline & \multicolumn{2}{|c|}{ ESCOLARIDADE } & \multicolumn{2}{c|}{ SEXO } & \multicolumn{3}{c|}{ IDADE } \\
\cline { 2 - 8 } & -ESC & + ESC & F & M & FAIXA A & FAIXA B & $\begin{array}{c}\text { FAIXA C } \\
\text { (CRIANÇAS) }\end{array}$ \\
\hline TR & 3 & 2 & 3 & 2 & 3 & 2 & 0 \\
\hline TNR & 12 & 8 & 15 & 13 & 13 & 7 & 8 \\
\hline TGC & 15 & 10 & 18 & 15 & 16 & 9 & 8 \\
\hline TER & & & & &
\end{tabular}

Legenda: $\mathrm{TR}=$ Total de resposta, $\mathrm{TNR}=$ Total de não resposta, $\mathrm{TGC}=$ Total geral de colaboradores.

As não respostas na dimensão diastrática (escolaridade) ${ }^{9}$ totalizam vinte ocorrências, sendo doze no parâmetro -ESC (menos escolarizado) e oito no +ESC (mais escolarizado). Na dimensão diagenérica (sexo), as mulheres totalizam quinze não respostas, e os homens treze, somando ambos vinte e oito registros. Na dimensão diageracional (idade), documentam-se treze ocorrências na faixa etária $\mathrm{A}$, sete na $\mathrm{B}$ e oito na $\mathrm{C}$. Essas dimensões, com os dados quantitativos para rótula, apresentam-se da seguinte maneira:

Tabela 2. Não resposta por dimensão social/rótula

\begin{tabular}{|l|c|c|c|c|c|c|c|}
\hline \multicolumn{10}{|c|}{ RÓTULA } \\
\hline & ESCOLARIDADE & \multicolumn{2}{c|}{ SEXO } & \multicolumn{3}{c|}{ IDADE } \\
\cline { 2 - 8 } & - ESC & + ESC & F & M & FAIXA A & FAIXA B & $\begin{array}{c}\text { FAIXA C } \\
\text { (CRIANÇAS) }\end{array}$ \\
\hline TR & 3 & 3 & 2 & 6 & 4 & 0 & 0 \\
\hline TNR & 12 & 7 & 13 & 12 & 12 & 9 & 8 \\
\hline TGC & 15 & 10 & 15 & 18 & 16 & 9 & 8 \\
\hline Legenda: TR $=$ Total de resposta, TNR = Total de não resposta, TGC = Total geral de colaboradores. \\
\hline
\end{tabular}

8 Os primeiros dados do ALiPAI foram coletados por dois pesquisadores do projeto GeoLinTerm que atuam também no ALiB, projeto por meio do qual tais pesquisadores puderam participar de vários Workshops.

9 Para a análise do fator extralinguístico escolaridade, foram desconsideradas as oito crianças pelo fato de elas estarem regularmente matriculadas na escola e cursando séries distintas. 
Do total de não resposta, dezenove ocorrências, doze documentam-se no parâmetro -ESC, e sete no +ESC. Já na dimensão diagenérica, as não respostas somam vinte e cinco registros, sendo treze para o sexo feminino e doze para o masculino. A derradeira das dimensões sociais controladas totaliza vinte e nove ocorrências de não resposta, sendo doze na faixa etária $\mathrm{A}$, nove na $\mathrm{B}$, e zero na $\mathrm{C}$, nestas duas últimas faixas etárias a não resposta é categórica, ou seja, idosos e crianças não conseguiram responder à questão 117 (rótula).

Apesar do alto índice de não resposta nas três variáveis sociais controladas, para ambos os itens lexicais estudados, nota-se uma pequena tendência, desprezível, observados os dados das tabelas 1 e 2, em que as respostas mais positivas se estabelecem na faixa etária $\mathrm{B}$ e na escolaridade. Parece que o universo lexical de faixas etárias que têm passado por vivência temporal mais extensa, se comparado ao das crianças ou ao dos jovens adultos, apresenta um conhecimento sobre o mundo ligeiramente mais amplo. Será que a não resposta não tenderia a diminuir, se o número de entrevistados dos mais escolarizados e das faixas etárias mais avançadas fosse maior? Essa é uma hipótese de investigação válida para outros estudos no mesmo espaço geográfico.

Uma outra constatação diz respeito ao registro da não resposta nos pontos 1/TI Trocará e 3/TI Sororó, para pálpebras, e no ponto 2/TI Nova Jacundá, para rótula, que é categórico em todas as dimensões sociais consideradas, fato que não pode passar despercebido ao se retomar as cartas 001 e 002 sob uma perspectiva mais pontual. Se, por um lado, a hipótese da influência diageracional e diastrática pode, mediante pesquisas de campo mais robustas, mostrar que a competência lexical pode ser influenciada por essas duas variáveis, por outro, nota-se um contraponto diatópico e diacultural que pode neutralizar a influência da idade e da escolaridade no caso de pesquisas geolinguísticas que não investigam a mobilidade populacional no perfil dos colaboradores (pesquisas topoestáticas). Isso sugere que cada dimensão de pesquisa geolinguística pode ter seu peso sobre o comportamento de dados lexicais. No caso das etnias Asuriní, Suruí (pálpebras) e Guaraní Mbyá (rótula), parece que o universo lexical dos indivíduos não favorece a aparência das variantes lexicais que podem ser registradas em outras etnias que apresentam configurações sociais diferentes. É um fator que evidentemente pode gerar não respostas e tornar a avaliação geolinguística da variação lexical um fenômeno multifatorial e consequentemente dependente de critérios de análise que justifiquem abordagens geossociolinguísticas mais amplas.

Essa constatação da necessidade de uma investigação multifatorial a partir de uma metodologia geossociolinguística, a exemplo dos estudos de Razky (1998, 2010, 2015, 2017, 2019), é corroborada quando se lança mão de técnicas de sugerência (Thun 1996, 1998), que favorecem um olhar mais profundo sobre o universo lexical presente e/ou utilizado num determinado ponto de inquérito. É interessante mencionar, nesse sentido, que sugestões de resposta foram dadas 
aos colaboradores Asuriní entrevistados e somente a colaboradora 2FA (mulher, faixa etária $\mathrm{A}$, escolarizada a partir do $1^{\circ}$ ano do ensino médio), que é professora na escola da aldeia Trocará, assegurou ter ouvido falar na denominação pálpebras, mas sem afirmar que a usa. Entre os Suruí, as colaboradoras 1FB (mulher, faixa etária $\mathrm{B}$, não escolarizada ou escolarizada até a $4^{\mathrm{a}}$ série) e $2 \mathrm{FB}$ (mulher, faixa etária $\mathrm{B}$, escolarizada a partir do $1^{\circ}$ ano do ensino médio), respectivamente, disseram ter ouvido camará (branco/não índio) falar em capela e pálpebras/ capela, mas que tais denominações não são usadas na aldeia ${ }^{10}$, e que para elas se referirem à parte do corpo em questão usam mais a forma lexical da língua indígena ${ }^{11}$. Assim, chama a atenção na fala de alguns Suruí da faixa etária B expressões tais como: "não sei como eles [os camarás] chamam", "não sei como é camará" e "camará às vezes fala". No caso de rótula, em Nova Jacundá, onde ocorreu o terceiro registro categórico de não resposta, destaca-se a da expressão "não sei", quando da resposta à questão 117. Relatos desse tipo também se aplicam as demais etnias, conforme podem mostrar os trechos de entrevista a seguir:

INQ. - E essa pele que cobre os olhos?

COL.- Pele que cobre os olhos... Não. Não tô lembrado não.

INQ. - Já ouviu falar em pálpebras?

COL.- Já ouvi falar de pálpebras.

INQ. - Mas vocês usam aqui?

COL.- Não. Não usa não.

(Colaborador 2MA, Guaraní Mbyá)

INQ. - E essa pelezinha que cobre o olho como é que chama?

COL.- Não sei não.

INQ. - Já ouviu falar em capela dos olhos?

COL.- Não.

INQ. - Pálpebras? Não ouviu falar nisso não?

COL.- Pálpebras já.

INQ. - Já, né? Mas você usa essa palavra?

COL.- Não.

INQ. - Não, né?

10 A colaboradora 2FB afirma que as denominações pálpebras e capela não são usadas na aldeia e, logo em seguida, reitera a sua fala: "pode usar né? Mas eu não tô lembrada".

11 Para este estudo, que tem como objeto principal o português falado por indígenas, considerou-se apenas os dados relativos à língua portuguesa. Entende-se que a consideração dos dados referentes às línguas indígenas requer conhecimento efetivo das mesmas. 
(Colaborador, 1MA, Guajajára)

INQ. - Tem um ossinho que fica bem aqui em cima do joelho, que ele se mexe pra lá e pra cá, como que chama esse ossinho?

COL.- Me esqueci o nome desse bicho aí... joelho... cartilagem... cartilagem

INQ. - Já ouviu falar em rótula?

COL.- Não. Não.

INQ. - Pataca?

COL.- Não. Também não.

(Colaborador, 2MA, Guajajára)

INQ. - O osso redondo que fica na frente do joelho, esse ossinho aqui?

INQ. - [tenta pronunciar uma forma linguística em língua indígena] ... Nós aqui nós chama coisa, joelho.

INQ. - Pra tudo, né?

COL.- Tudo.

INQ. - Não tem um nome pra esse ossinho separado assim, não?

COL.- [colaboradora tenta mais uma vez pronunciar a mesma forma linguística em língua indígena e, depois de um tempo, consegue] ...que é aquele lá de dentro.

INQ. - Em português, tem um nome pra ele?

COL.- Não. Conheço não.

Parece mesmo que o conjunto de variantes lexicais que podem denominar os itens lexicais em análise ainda não faz parte da competência lexical ativa dos indígenas entrevistados. Contudo, surge uma outra variável de análise, pois alguns dos participantes da pesquisa deram denominações para pálpebras e rótula em língua indígena, especialmente os da faixa etária $\mathrm{B}$. Essa faixa etária de colaboradores tende a apresentar maior proficiência em língua indígena, de acordo com os resultados do estudo de Costa (2018), que analisou os dados coletados com o auxílio do QS do ALiPAI.

A dimensão que parece caracterizar as etnias pesquisadas é a variável dialingual. De fato, a não resposta pode mostrar que sua correspondente existe na competência lexical indígena nas áreas investigadas. Essa dimensão de uma competência bilíngue é interessante, pois mostra que, numa pesquisa em ambiente monolingual, a dimensão dialetal pode explicar o problema da não resposta, mas, numa investigação dialingual, a não resposta pode indicar ou a presença de uma variante dialetal na dimensão monolingual ou uma variante dialingual que necessita de um grau de atenção maior do inquiridor para poder evitar o registro da não resposta antes de afirmar que aquele conceito não tem denominação naquela região. 
A não resposta, então, torna-se um ponto de reflexão importante, firmandose mesmo como uma questão metodológica, que remete o pesquisador não só à avaliação dos instrumentos de coleta de dados (quantidade de perguntas, o modo como essas perguntas são formuladas etc.), mas também à necessidade de um rol mais diversificado de variáveis a serem controladas. Ademais, é válido pensar num universo maior de colaboradores, como uma possibilidade de adquirir melhor condição de estudo da não resposta.

Ainda na perspectiva de fatores sociais, Aguilera \& Yida (2008) situam o conhecimento de mundo. Para as etnias consideradas neste estudo, por uma série de fatores, o acesso a bens materiais, sociais e culturais tende a ser reduzido, o que pode implicar na bagagem lexical dos colaboradores. De fato, por exemplo, quando perguntados a respeito do modo como se dava o contato deles com os meios de comunicação - TV (programas preferidos), rádio (programas preferidos), leitura de jornal e revista -, bem como de que maneira participavam de diversões - cinema, teatro, shows, manifestações folclóricas, futebol etc. -, as respostas foram variadas em tipologia e quantidade de horas que se prendem a eles, destacando-se, por exemplo, os noticiários e o futebol. Outro ponto que se enquadra nessa perspectiva, é o fator mobilidade; os homens tendem a sair mais das aldeias, os jovens tendem a sair para estudar, quando em sua comunidade não é possível completar os estudos, entre outros.

Em relação aos fatores de natureza psicológica, em que se constatam comportamentos diversos (cansado, tímido, doente, desinteressado etc.) na ausência de resposta, reflete-se, neste estudo, a pertinência do fator esgotamento ou cansaço do colaborador como fator que pode resultar na não resposta entre os indígenas entrevistados, uma vez que a aplicação do QSL, o maior dos questionários em número de questão (202), sucede a do QS e a do QFF, além da ficha do colaborador. A percepção da extensão do QSL pode influenciar a não resposta.

No que tange aos fatores de natureza pessoal, que são vinculados ao cotidiano dos colaboradores, os indígenas têm compromissos e agendam atividades: vão à escola, ao supermercado, participam de cerimônias religiosas, cuidam dos afazeres que lhe dizem respeito etc. Uma preocupação com agendas pré-programadas pode resultar em ansiedade e explicar em parte o processo da não resposta.

Uma outra hipótese trazida para análise da não resposta dentro do contexto da pesquisa geossociolinguística com indígenas é a que foi levantada por Oliveira, Costa \& Paz (2018). As autoras colocaram na base dos vazios dialetológicos, ou a não resposta, a pressão: a) de fatores sociais, b) da avaliação social das formas linguísticas e c) do fator histórico-cultural.

Em relação aos fatores sociais (a), efetivam-se como ponto de discussão nas duas pesquisas sobre não resposta apresentadas na seção "A não resposta nos inquéritos de estudos geolinguísticos" deste artigo, de modo que ambas as 
abordagens corroboram a reflexão da dimensão social dos dados analisados neste estudo.

No que diz respeito à avaliação social das formas linguísticas (b), buscaramse em Ferreira (2004) e Houaiss (2011) os registros das formas lexicais esperadas como resposta para pálpebras/capela dos olhos e rótula/pataca. Pálpebras e rótula estão dicionarizadas na obra lexicográfica de ambos os autores mencionados com a mesma acepção do QSL, destacando-se o verbete relativo à rótula, na obra de Houaiss, que informa que em anatomia geral ortopédica o termo rótula foi substituído pelo termo patela. Capela dos olhos não está dicionarizada em nenhum dos dicionários consultados, e pataca encontra-se dicionarizada nos dois, mas com outra acepção ${ }^{12}$.

Obviamente, as variantes consideradas como padrão pertencem à variedade culta da língua, são prestigiadas e conservadoras. Em situação de entrevista, o desconhecimento dessas variantes pode contribuir para a ausência de variantes consideradas como não padrão. Essas variantes, por sua vez, tendem a se distanciar das variantes consideradas cultas, devido ao estigma e ao caráter inovador daquelas variantes que levam tempo para serem incorporadas num dicionário, sobretudo quando tem caráter local ou regional. Em outras palavras, o entrevistado pode ficar acanhado e omitir a forma linguística que usa no seu cotidiano.

Há ainda a influência da identidade local ou regional que pode impor uma norma local ou regional que pode favorecer variantes lexicais não dicionarizadas. É o caso das cartas lexicais analisadas 001 e 002 deste trabalho. As duas cartas mostram, por exemplo, que as variantes não dicionarizadas coro do olho, na TI Cana Brava, e bolacha (na TI Trocará) tendem a predominar, embora tenham poucas ocorrências. Trata-se aqui de formas populares que constituem uma norma local nessas comunidades ${ }^{13}$, enquanto que nas demais Terras Indígenas, para ambos os itens lexicais, a não resposta sobressai-se.

No que tange ao fator histórico-cultural, os povos indígenas investigados são marcados não só pela perda populacional, linguística e cultural, mas também pela luta por direitos, em todos os campos da vida humana. Nessa perspectiva, destaca-se a imposição da cultura do não indígena ao indígena, cujo processo é de natureza histórica. A imersão dos indígenas em um mundo dominado pela cultura dos não índios origina para as comunidades étnicas

12 De acordo com ambos os dicionários, em acepções comuns, pataca é definida como moeda antiga de prata com valor de 320 réis, utilizada em transações monetárias em Macau e Timor. O uso da forma lexical pataca para designar o osso redondo que fica na frente do joelho pode dar-se por analogia à forma da moeda.

13 Entendemos o conceito de norma de acordo com Faraco (2008: 40), segundo o qual norma "é o termo que usamos, nos estudos linguísticos, para designar os fatos de língua usuais, comuns, correntes numa determinada comunidade de fala. Em outras palavras, norma designa o conjunto de fatos linguísticos que caracterizam o modo como normalmente falam as pessoas de uma certa comunidade, incluindo [...] os fenômenos em variação." 
diversas necessidades, mas o direito aos principais bens desse universo cultural não é de fácil conquista e, quando o acesso a algum bem é adquirido, este acaba dando-se de forma precária. Assim, o modo como os bens culturais, os conhecimentos, chegam até os indígenas pode interferir na questão da não resposta.

Os dados analisados neste estudo indicam que o perfil do informante pode, numa pesquisa quantitativa robusta sobre faixa etária e escolaridade, explicar a não resposta. Os resultados decorrentes da análise desses dados, no entanto, são muito tímidos para elucidar a não resposta, por isso, quase não implicam na sua não ocorrência, o que foi observado por meio do fato de as discrepâncias quantitativas entre um e outro parâmetro social não serem muito altas, dentro de cada dimensão considerada. O conhecimento de mundo dos indígenas pode contribuir para a ausência de resposta, tendo em vista suas vivencias. $\mathrm{O}$ instrumento de coleta de dados, no caso o QSL, pode influenciar quanto à questão do cansaço, uma vez que apresenta 202 questões e que três outros instrumentos metodológicos o antecedem. A habilidade do pesquisador não parece ser o caso, pois as duas questões consideradas não impõem dificuldades ao inquiridor. A avaliação social das unidades linguísticas parece perder a força, pois as formas não dicionarizadas, embora com baixo número de ocorrências, tendem a predominar em algumas das Terras Indígenas investigadas. $\mathrm{O}$ fator histórico-cultural das comunidades étnicas pesquisadas pode interferir, tendo em vista os processos pelos quais passaram ao longo da história.

\section{Considerações finais}

Neste artigo refletiu-se o fenômeno da não resposta no português falado nas Terras Indígenas Asuriní do Tocantins, Guaraní Mbyá, Suruí Aikewára, localizadas no Pará, e Cana Brava, localizada no Maranhão a partir de dois itens lexicais, cuja imagem cartográfica despertou a atenção pelos vazios lexicais diatópicos registrados nas cartas 001 e 002 . Na base dessa reflexão estava o interesse em discutir o porquê de o dado não resposta ter sido tão significativo para pálpebras e rótula. Adotaram-se as hipóteses levantadas por Aguilera \& Yida (2008) e por Oliveira, Costa \& Paz (2018), quando do estudo da não resposta com base nos dados do ALiB, para tecer tal discussão. Todas elas foram analisadas numa perspectiva voltada para a pesquisa geolinguística em áreas indígenas.

O número de não resposta é expressivo tanto para pálpebras quanto para rótula. Seria interessante observar outros itens lexicais do campo semântico Corpo humano para se ter uma imagem mais ampla da não resposta e, consequentemente, da absorção desse léxico pelos indígenas participantes desta pesquisa. Outro estudo oportuno seria o que se voltaria para o registro desses 
itens no português falado por não indígenas das áreas investigadas, buscando observar se nessa variedade da língua a não resposta também é significativa.

No tocante ao fator metodológico, no trato da não resposta, pontua-se a importância de uma metodologia geossociolinguística que focalize dimensões mais complexas de investigação lexical e a representação quantitativa mais ampla do universo de informantes para sua melhor análise. A não resposta é uma questão importante para a geossociolinguística, uma vez que ela procura integrar uma análise multifatorial de grupos de fatores oriunda de uma microssociolinguística que, por sua vez, precisa de uma investigação de arealidade que reflita um caráter complexo da investigação sobre a variação lexical e que, consequentemente, cerque o fenômeno da não resposta de forma mais profunda. A título de exemplo, pode-se citar o conceito de agrupamento lexical desenvolvido por Razky et al. (2012, 2015, 2017, 2019), que vem mostrando que espaços dialetais menores demonstram flutuações lexicais interessantes quando abordadas em termos de agrupamentos lexicais (nano, micro ou macro) que podem mapear o espaço geográfico de não resposta dentro de um contínuo de agrupamentos.

\section{Referências}

Aguilera, Vanderci de Andrade \& Yida, Vanessa. 2008. "Projeto ALiB: uma análise das respostas e das não-respostas de informantes das capitais". Signum: Estudos da Linguagem, Vol. 11, No. 2: 15-31.

Cardoso, Suzana Alice Marcelino da Silva. 2016. Dialetologia. In: M. C. Mollica \& C. Ferrarezi Júnior (Orgs.). Sociolinguística, sociolinguísticas. São Paulo: Contexto, pp. 13-22.

Comitê Nacional do Projeto ALiB. 2001. Atlas Lingüístico do Brasil: questionários. Londrina: Ed. UEL.

Costa, Eliane Oliveira da. 2018. Estudo Geossociolinguístico do Léxico do Português Falado em Áreas Indígenas de Língua Tupi-Guarani nos Estados do Pará e Maranhão. 2018. Tese de Doutorado. Universidade Federal do Pará.

Faraco, Carlos Alberto. 2008. Norma culta brasileira: desatando alguns nós. São Paulo: Parábola Editorial.

Ferreira, Aurélio Buarque de Holanda. 2004. Novo Dicionário Aurélio da Língua Portuguesa. Curitiba: Positivo.

Houaiss, Antônio, Villar, Mário de Sales \& Franco, Manoel de Melo. 2001. Dicionário Houaiss da Língua Portuguesa. Rio de Janeiro: Objetiva: Instituto Antônio Houaiss de Lexicografia.

Oliveira, Marilucia Barros de, Costa, Celiane Sousa, Paz, Flávia Helena da Silva. 2018. "Reinterpretando Vazios Dialetológicos no Norte do Brasil". Signum: estudos da Linguagem, Vol. 21, No. 1: 15-31. 
Radtke, Edgar \& Thun, Harald. 1996. Neue Wege der romanischen Geolinguistik: Eine Bilanz. In: E. Radtke \& H. Thun (Ed.). Neue Wege der romanischen Geolinguistik: Akten des Symposiums zur empirischen Dialektologie. Kiel: Westensee-Verl, pp. $1-24$

Razky, Abdelhak. 1998. O Atlas geo-sociolinguístico do Pará: abordagem metodológica. In: V. de Andrade Aguilera. (Org.). A geolinguística no Brasil: caminhos e perspectivas. Londrina: Eduel, pp. 155-164.

Razky, Abdelhak. 2010. "Uma perspectiva geo-sociolinguística para a análise do status da variável $<\mathrm{s}>$ em contexto pós-vocálico no nordeste do estado do Pará”. Estudos Linguísticos - Programa de Pós-Graduação em Língua e Cultura, Programa de PósGraduação em Literatura e Cultura da Universidade Federal da Bahia, No. 41:169188.

Razky, Abdelhak \& Guedes, Regis José da Cunha. 2015. Le continuum des regroupements lexicaux dans l'Atlas Geossociolinguístico do Pará (ALiPA). In: M. Contini \& J-P, Lai (Orgs.). La géographie linguistique au Brésil. Geolinguistique. Grenoble: ELLUG, pp.149-162.

Razky, Abdelhak \& Sanches, Romário Duarte. 2016. "Variação geossocial do item lexical riacho/córrego nas capitais brasileiras". Gragoatá, No.40: 70-89.

Razky, Abdelhak, Coimbra, Diego dos Santos \& Costa, Eliane Oliveira da. 2017. "Variação léxico-semântica e agrupamento lexical do item cambalhota no Atlas Léxico Sonoro do Pará (ALeSPA)". Lingua e Instrumentos Linguísticos, Vol. 40: 151-169.

Razky, Abdelhak \& Coimbra, Diego dos Santos. 2019. "Agrupamentos fonéticos da vogal média anterior /e/ em posição pretônica no Atlas Linguístico de Rondônia (ALIRO)". Cadernos de Estudos Linguísticos, Vol.61: 1-19.

Razky, Abdelhak, Guedes, Reges José da Cunha \& Costa, Eliane Oliveira da. "A Pesquisa Geolinguística em Áreas Indígenas Brasileiras: desafios e estratégias". Signum: Estudos da Linguagem, Vol. 21, No. 1: 126-138.

Thun, Harald. 1998. "La geolinguística como linguística variacional general (con ejemplos del Atlas linguístico Diatópico y Diastrático do Uruguay". In: Atti del Congresso Internacizionale di Linguística e filologia romanza, Palermo, 1995, 701729. Palermo: Universitá di Palermo. 